\title{
Torres Rodríguez, Oswaldo \& Apaico Alata, René Marcial (2017). Simbolismo y control social en TRATANAKUY. Fondo Editorial: Universidad de Ayacucho Federico Froebel.
}

Los autores exploran la historia enfocando el proceso de control social en las diferentes culturas del mundo y sus numerosas manifestaciones en aras de mantener la conducta y la mesura de sus pobladores. El trabajo distingue los inicios de la humanidad en su proceso natural de hominización, estableciendo varias hipótesis: "Una de estas respuestas fue que el Hombre es un ser simbólico" (p. 17).

El libro posee cuatro capítulos. La "Introducción" abarca aspectos generales de la investigación; "Tratanakuy", refiere la esencia central que recopila la fidedigna dimensión de sus trabajos; "funciones del tratanakuy", su axiomático sentido y la razón de su supervivencia cultural sobre el control social y, "los valores en tratanakuy" donde aterrizan en diversas conclusiones en discusión con otras investigaciones. Aquí se manifiesta la sociedad guiada en función de la cultura de cada pueblo, independientemente de su evolución histórica. El paralelismo y su correspondiente discusión es fundamental, triangulando con diferentes autores referenciales como Guamán Poma de Ayala, reconocido intelectual del control social en la historia peruana citado con frecuencia por los autores.

Sobre el control social los autores consignan advertencia especial a Michel Foucault con su trabajo Vigilar y castigar, que sustenta la discusión a lo largo del libro, complementado con La condición humana de Hannah Arendt; bibliografía referida en varios pasajes, estas son algunas fuentes de trascendencia universal, sin relegar a otros autores que analizaron críticamente el tema. La línea del libro está condimentada con diversos escenarios de pueblos que practican semejantes formas de control social en el territorio peruano; elaboran un símil con San Juan Bautista, distrito ayacuchano más antiguo, así: "Por ejemplo, la sanción de la bigamia en el Distrito de Chongos Bajo... la 'Quema de Judas' en la época de Semana Santa donde se prepara a un muñeco muy semejante a la persona que transgrede la prohibición del incesto" (p. 24). A ello se suman otras costumbres 
con objetivo moralizante, acotándose la Danza del Huacón que supervisa el aseo del domicilio de las familias, quienes al no practicar la limpieza son castigados a latigazos públicamente, o los Avelinos en Tunan Marca. El espacio geográfico establecido por los autores no es ajeno a las diferentes formas de vigilancia social en el interior del territorio peruano.

El control social no exceptúa los escenarios internacionales como las culturas clásicas de Grecia y Roma sobre los derechos consuetudinarios establecidos por los pueblos; estas costumbres son vivencias inherentes a los hombres: "Tratanakuy es una manifestación de una de las esferas culturales de la moral, derecho y el arte de los pueblos quechua del sur peruano; porque, en su composición están planteadas normas morales, jurídicas y formas de expresión literaria" (p. 30). Esta manifestación cultural y de vigilancia social aún se mantiene en muchas poblaciones peruanas, exonerando la intervención jurídica. No existe una sociedad exenta de conflictos sociales, por tanto, es necesaria la vigilancia.

Tratanakuy es control social con exposición pública, pues si el poblador transgrede las buenas costumbres es insultado con ocasión especial de los festejos de San Juan Bautista, aparentando insultar al Santo. La costumbre del tratanakuy se mantiene en Huancavelica, Ayacucho, Apurímac y Cusco, pero en el caso de Huamanga tiene preponderancia simbólica el "sermón" a las cinco de la mañana, como una especie de ceremonia familiar por falta moral. La palabra tratanakuy es un término quechuizado que significa relacionarse con otra persona, sea bien o mal sobre un determinado asunto.

El segundo capítulo es la esencia de la investigación donde los autores acopian información histórica de la época inca, de la conquista y de la colonia, agregando las prácticas actuales de la supervivencia de control social. El acontecimiento de las festividades de San Juan coincide en diferentes partes del mundo junto con las manifestaciones culturales de cada pueblo; así lo describen las crónicas peruanas: “[...] al Inti Raymi, culto solar practicado por los incas 
en el Cusco, a la quema de ropa vieja el 23 de junio de cada año en la ciudad de Huancayo-Perú, en la convicción que con el fuego se limpia todo lo negativo del año que pasó y una vez purificado renace una nueva vida...” (p. 51). Los autores concluyen que el tratanakuy no es de origen europeo; aunque se engarce con las prácticas y rituales religiosos por su semejanza de forma, los parecidos de su práctica han sido compartidos y no se puede negar su origen prehispánico.

Las celebraciones del agua y del sol, deidades prehispánicas, coinciden con la fecha del gobierno incaico, exactamente el 24 de junio, que organizaba el Inti Raymi en la plaza de Waqaypata del Cusco-Perú. En los meses siguientes se festejaba a la diosa agua, que estaba considerada de menor jerarquía. Actualmente, se mantiene con un sincretismo o hibridación en el valle del Mantaro (JunínPerú), cada 8 de septiembre en alusión sincrética a la Virgen de Cocharcas. Del mismo modo, en la Selva peruana se observa la fiesta de San Juan, al igual que su plato denominado juane en alusión al santo, además de la danza de la boa, la danza de las Amazonas y la danza de los Tulumayos, todas en honor de San Juan.

En tanto, las formas de expresión cultural de control social en Ayacucho fueron interrumpidas por Sendero Luminoso con el conflicto armado interno, suceso trágico para los quechuas: "El informe de la Comisión de la Verdad reportó que de las 72 mil personas muertas el 74 por cierto fueron de color cobrizo. El terror desatado por esta guerra ha dejado como herencia enfermedades psíquicas casi insuperables hasta la actualidad" (p. 59). Sin embargo, la población actual de San Juan Bautista aún practica el tratanakuy como supervivencia cultural; la encuesta hecha por los autores arroja que el 50\% de la población considera que son insultos para corregir el mal comportamiento y los defectos de las personas, principalmente de autoridades como el alcalde.

En este capítulo se clasifican categorías sobre el tratanakuy de acuerdo con la importancia social de la cultura actual. En lo referido a insultos al cuerpo humano recopilaron 144 expresiones en quechua que perviven en el control social, todas traducidas al español, en donde, por supuesto, no tienen el mismo 
significado ni valor expresivo, como señalan sus autores. El significado literal o metafórico del quechua varía en la traducción; sin embargo, están fundamentadas las expresiones más relevantes. Ejemplo: "San Juan, San Juan / qantachu, qantachu / nisurqanki runtusapa nispa" (p. 63) (San Juan, San Juan, a ti, a ti, te han dicho que tienes testículos muy grandes). Estas formas de expresión son metafóricas; el aspecto imprescindible de todo tratanakuy inicia así: "San Juan, San Juan: qantachu, qantachu nisurqanki...", ahí remata la alusión ofensiva que desea proferir al contrincante o al aludido. En lo referente a insultos a la infidelidad se encuentran 12 expresiones de ofensa: "Parte de la naturaleza humana es la fidelidad que debe caracterizar al ser humano quechua” (p. 94). Por tal razón está presente la vigilancia del poblador quechua. Otra clasificación es por la higiene del poblador, donde destacan 19 ejemplos de tratanakuy vigentes actualmente. En la cultura quechua e inca se condenaba la ociosidad, para lo que dedicaron 24 formas de control social, siempre con el San Juan, San Juan. El alcoholismo es un mal social, se plantean 3 formas de vigilancia para sus pobladores. Convivimos en la vida del chisme y producto de las anteriores formas de control social, la privacidad es importante, estableciéndose 5 controles de tratanakuy. La propiedad privada es menester; el hurto tiene 13 controles sociales con San Juan, San Juan. Finalmente, todo poblador debe ser mesurado, así el control de la viveza tienen 18 formas de vigilancia.

El tratanakuy fue establecido en 8 categorías con el fin de sustentar las analogías y las homologías. La experiencia de tratanakuy, actualmente, es una terapia colectiva y permite descargar lo reprimido durante el año, siendo el mejor motivo la fiesta patronal en honor de San Bautista. Finalmente, los autores consideran que los aspectos jurídicos de una nación se basan en las costumbres de los pueblos; por ende, la valoración del tratanakuy es primordial en el sentido de la colectividad, descartando la individualidad de la cultura quechua. Sin duda, el libro posee aspectos negativos, siendo identificable las costumbres sexistas del machismo en el tratanakuy, también referencias de otras culturas. La historia demuestra el machismo en varias formas de control social, sobrevalorando al 
varón en desmedro de las mujeres. Actualmente, el tratanakuy tiene fines festivos y turísticos para el distrito de San Juan Bautista.

En suma, el libro pretende exponer cómo se controló la población a falta de las leyes jurídicas que, por cierto, aún practican muchas comunidades del territorio peruano. La investigación está sustentada con fuentes bibliográficas confiables para su discusión y su respectiva argumentación para relacionarla con los fenómenos de vigilancia mundial. No obstante, la vigilancia fue prioritaria para todas las sociedades con sus diversas manifestaciones; por tanto, los autores cierran el libro con una cita amplia de Foucault, referente indispensable sobre la vigilancia y castigo.

\section{Referencias bibliográficas}

Arendt, H. (2005). La condición humana, [7ª reimpresión]. Madrid: Paidós.

Guamán Poma de Ayala, F. (1980). El primer nueva corónica y buen gobierno. Ciudad de México: Siglo Veintiuno Editores, Instituto de Estudios Peruanos.

Foucault, M. (1976). Vigilar y castigar. Ciudad de México: Siglo Veintiuno Editores.

\section{Edgar Gutiérrez Gómez}

Universidad Nacional Autónoma de Huanta, Ayacucho, Perú

Contacto: egutierrez@udaff.edu.pe

https://orcid.org/0000-0001-9485-1284 